\title{
A Short Review of Recent Trends
}

\author{
By Leslie B. Patrick, M.B., Ch.B., F.R.C.S.Ed., F.R.C.O.G. \\ Senior Consulting Surgeon, Fessop Hospital for Women, Sheffield
}

In Britain, the frequency of eclampsia has diminished steadily during the last 20 years, as judged by the Registrar General's mortality rates for the hypertensive toxaemias of late pregnancy. In the City of Sheffield there were ten deaths due to eclampsia 1936-1945, and four deaths 19461955. In consequence few obstetricians have had the opportunity to make a concentrated study of the newer methods of treatment. The careful ante-natal care which is given to almost every pregnant woman has shifted the emphasis to the treatment of early pre-eclampsia and chronic hypertension. Such cases adequately treated rarely deteriorate to the extent of developing eclampsia, though fits do occasionally occur in patients with only mild pre-eclampsia. Fulminating cases, where there has been no obvious sign even a few hours before, and cases occurring more than 48 hours after delivery, are also rare.

There is no standard definition of imminent eclampsia, though most obstetricians would agree when confronted with an individual case. The ominous symptoms of headache, visual disturbances, vomiting, epigastric pain, oliguria, and. rarely slight jaundice are well known but not always present. A raised blood pressure, albuminuria and oedema are usually present but again there are exceptions. It is difficult to know the most important single feature in a case of pre-eclampsia which is likely to progress to eclampsia. It is probable that the level of hypertension is the most important; a systolic blood pressure of $160 \mathrm{~mm}$. $\mathrm{Hg}$. is often accepted, and Norman Morris (1955) has stressed that $100 \mathrm{~mm}$. $\mathrm{Hg}$. is the important diastolic level.

\section{Etiology}

It is not possible in the compass of this article to discuss fully the theories of the cause of preeclampsia, but in view of the promise shown recently by the use of hypotensive drugs in treatment, it may be useful at the risk of simplification to examine how the method fits in with existing theory.
It has been shown by Kellar and Sutherlando (I94I), that the hypertension of pre-eclampsia is 3 produced by a humoral agent, though the hypertension can be influenced by neurogenic means. $N$ For many years the placenta has been suspected as $\omega$ the source of the ' toxin.' Young (19I4 and I942) $\omega$ believes that autolytic products formed in red infarcts of the placenta are the cause, but it is 0 doubtful if infarcts are commoner in eclampsia than in normal pregnancy.

More recently attention has focused on ischaemia of the placenta causing anoxia of the multi-functional trophoblast leading to degenero tive changes, which may -influence the pro eclamptic process. The mechanism by whis $\overrightarrow{0}$ ischaemia is produced has been discussed or several authors including Becker (1948), Bastiaanșe and Mastboom (1950). Pre-eclampsia is commoner in conditions where relative ischaemia is present, hydramnios, multiple pregnancy, primiparity, obesity, essential hypertension and severe $\frac{\circ}{\otimes}$ maternal anaemia. Wettley (1938) found a $\cong$ hypoplastic uterine vascular system at autopsy in $\overrightarrow{\overrightarrow{0}}$ about one quarter of cases of eclampsia. It is known that blood oestrogens are at a low level in pre-eclampsia suggesting premature senility of the placenta, or a hypoplastic vascular supply to the uterus in pregnancy may lead to an inadequate supply of steroid hormones from the placenta for 3 the normal development of the uterine vessels. Bastiaanse and Mastboom sum up as follows: $\frac{O}{3}$ ' toxaemia could be caused by any disturbance in the normal relationship of the volume of blood 9 carried to the placenta per unit of time, and the $\frac{D}{O}$ quantity of placental tissue. Toxaemia is then dependent on an absolute or a relative insufficient $N$ blood supply to the placenta .. In this way the toxaemia of late pregnancy is a sign of insufficient 0 adjustment of the mother's organism, especially $\mathfrak{\omega}$ her vascular system to the demands of pregnancy. In other words, the toxaemia of late pregnancy is 0 a disease of insufficient adaptation.'

Brown and Veall (1953), by measuring the rate of radio-active sodium clearance from the placental 
circulation have shown that in pré-eclampsia and chronic hypertension the rate of maternal blood flow is about one-third of the normal maternal placental blood flow. Morris et al. (1955) carried this work farther by measuring the uterine blood flow in normal and in pre-eclamptic pregnancies. They found that the effective blood flow is about half the normal in mild, and only quarter the normal in severe pre-eclampsia, and that it is somewhat decreased in twin gestation. They also measured the effect of exercise upon the uterine blood flow and found that in normal patients it is almost halved, and in pre-eclamptic patients it is reduced by about one-third. This is of great significance as it is a common observation that the patient who begins to show signs of pre-eclampsia has been 'overdoing it ' and conversely the mild case often settles with bed rest. It is also accepted that rest prevents or delays the onset of preeclampsia in the chronic hypertensive. Morris (1955) also states that from his observations the reduction in uterine blood flow appears to be directly related to the increase in diastolic blood pressure; an increase of ro $\mathrm{mm}$. $\mathrm{Hg}$. is associated with a clearance rate which is only half that of the normal. In 84.I per cent. of 63 eclamptics the diastolic blood pressure was $100 \mathrm{~mm}$. or over. In the Jessop Hospital, of 82 consecutive cases of eclampsia in which there was a record of the diastolic blood pressure before the onset of fits 82.9 per cent. had a diastolic blood pressure of $100 \mathrm{~mm}$. Hg. or over.

Thus it seems reasonable to assume that the hypertension characteristic of pre-eclampsia is produced by arteriolar spasm probably caused by a humoral agent derived from an anoxic placenta. In the kidney this leads to glomerular changes which cause albuminuria, and a reduced filtration rate.

Neurogenic factors may also play a part in renal pathology. Sophian (1953) has presented experimental evidence that the resistance of the uterus to stretching causes a utero-renal reflex producing ischaemia of the type described by Trueta.

Endocrine factors are concerned in salt and water retention. Hawker in a personal communication to Kellar (1955) believes that antidiuretic hormone is increlased during pregnancy but that its effects are held in check by an enzyme derived from the placenta; and that a failure of this enzyme leads to the presence of active A.D.H. in the plasma of the severe pre-eclamptic. Lloyd et al. (1952) and Hughes et al. (1954) have shown that adrenal steroids are considerably increased in severe pre-eclampsia above that found at the same stage of normal pregnancy. It is well known that adrenal steroids cause sodium retention; and there is evidence that the adrenal cortex elaborates a secretion which can maintain hypertension. The primary cause of the increase of adrenal steroid in pre-eclampsia is not known.

McCall (1949) has shown that Cerebral Vascular Resistance is increased in pre-eclampsia, probably due to vasospasm; yet the body maintains an adequate cerebral blood flow. However, cerebral oxygen metabolism is significantly depressed during the coma of eclampsia.

Theobald (1955) has stressed the importance of dietetic deficiencies and mechanical factors (The Nutritional-Mechanical Hypothesis). The geographical distribution, the decrease in frequency following better ante-natal care including diet, and the occurrence of eclampsia three or four days after delivery lend support to this view.

Probably many factors are involved in the etiology of pre-eclampsia. Fatigue super-imposed upon and caused by mechanical factors associated with pregnancy, and sometimes nutritional deficiencies and developmental uterine vascular defects may produce anoxia of the trophoblast which in turn by a humoral mechanism causes the widespread changes associated with vasoconstriction and hypertension. In puerperal eclampsia, which is difficult to explain by any theory, is there proof that no trophoblastic tissue remains in the uterus or possibly elsewhere ?

\section{Mechanism of the Production of Fits}

All cases of pre-eclampsia do not progress to a stage of convulsions, and it is not clearly understood why some patients are more prone to convulsions than others. Stern and Burnett (1954) have enumerated the factors, any one of which may sensitize the patient: (I) A state of nervous hyperexcitability associated with the presence of cerebral oedema. (2) An excessive retention of sodium ions causing increased neuronal excitability. (3) A state of hypertension. The fit being a manifestation of hypertensive encephalopathy. Spasm of the central arterioles may initiate a convulsion. (4) A predisposition to fits shown by cerebral dysrhythmia.

Rowntree (1923) has caused fits in dogs by producing cerebral oedema, but oedema is not always present in eclampsia. Tatum (1954) has shown that there is a significant increase in sodium ions in the oedema fluid in pre-eclampsia, but there is no increase in the serum. The effect of this sodium retention may be due to the production of oedema rather than to an increase in neuronal excitability. Damage to capillary walls and in some patients hypoproteinaemia may be other factors which produce oedema. Increased adrenal cortical activity in pre-eclampsia and its effect on sodium retention has already been noted. Hypertensive encephalopathy may occur in the absence 
of oedema. Browne (1950) has suggested that oedema and hypertension are complementary, convulsions arising if there is much oedema without hypertension or marked hypertension without oedema. The immediate cessation of convulsions as a result of adequate hypotensive therapy suggests that hypertensive encephalopathy plays a major part in the production of fits.

Dysrhythmia is found in about 12 per cent. of the normal population and in 90 per cent. of epileptics between fits. It has been found in a high percentage of eclamptics. This led to the assumption that fits occurred in patients with cerebral dysrhythmia. James (1955) has pointed out that this concept of eclampsia would mean that all cases of severe pre-eclampsia showing cerebral dysrhythmia should be dealt with radically and promptly. He recorded the encephalograms of 5I eclamptics from a few months to 14 years after the attack, and 52 patients with pre-eclampsia were recorded as controls. Forty-three per cent. of the eclamptic tracings were abnormal and 28.8 per cent. of the controls. He concluded that he found no statistical support to the view that electroencephalography would be of direct value in the choice of treatment in cases of pre-eclampsia; but thinks that repeated tracings on the same patient would be worth while. Thus suggesting that an observed change in cerebral rhythm would indicate the probability of convulsions.

\section{Pathological Lesions in Eclampsia}

The lesions of eclampsia vary greatly in degree, and, according to different authors, greatly in frequency. There is also some confusion because it is not always stated whether a pre-existing nephritic lesion was present. Naked-eye examination of the kidneys may show a pale cortex and congested medulla; the liver shows subcapsular haemorrhages and scattered haemorrhages in the substance of the organ. In about one-third of cases cerebral lesions may be visible to the naked eye. These may be frank haemorrhages or petechial haemorrhages into the grey or white matter or the basal ganglia.

There is some dispute concerning the pathogenesis and the actual nature of the lesions as seen microscopically. In the liver the characteristic lesion consists of periportal haemorrhage with fibrin deposition and degeneration of the surrounding liver cells. Sheehan (1950) thinks that the renal lesion is essentially in the glomeruli; the endothelial cells of the capillary loops being swollen and laying down a network of fine fibrils. The epithelial cells over the loops are also swollen. He thinks the basement membrane is not thickened. The main afferent vessel in the stalk of the glomerular tuft shows similar endothelial fibril formation, whereas the afferent arteriole leading to the tuft is not affected. There is little $\frac{3}{8}$ change in the convoluted tubules, but the collect- $\propto$

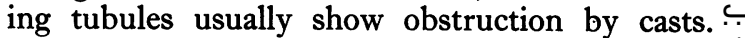
Sheehan considers that the lesions may be due to $\overrightarrow{\vec{s}}$ intermittent spasm in the afferent arteriole or in $\frac{9}{0}$ the glomerulus and that they may develop in a few days.

Govan (1954) reports changes in the kidneys $\frac{\mathrm{D}}{\vec{\phi}}$ comparable to those found in eclampsia in women $\propto$ dying during pregnancy or childbirth from causes $\tilde{\omega}$ unrelated to eclampsia.

McKay et al. (I953) consider that eclampsia, cortical necrosis and pituitary necrosis, show to a $\vec{\rho}$ varying degree a common histological pattern. $\frac{\text { o }}{\partial}$ They stress the presence of multiple fibrin thrombi in the afferent arterioles and in the glomerular stalk, in the periportal blood vessels of the liver, in the afferent vessels of the pituitary stalk and in other $\omega_{y}$ organs. They failed to demonstrate these fibrin $\omega$ lesions in a case of uncomplicated toxaemia who of died as a result of spinal anaesthesia, but did find lesions typical of eclampsia in patients dying from bacterial infections with no evidence of pre- $\vec{z}$ existing toxaemia. They suggest that these widespread lesions are an exhibition of the generalized $\mathbb{\Phi}$ Shwartzman reaction* and postulate that the preciptating agent is a substance derived from the $\mathbb{D}$ placenta.

They stress the idea, quoting Sheehan for. ज़ support, that there are two closely related but nof identical lesions with sufficient differences to warrant considering them separately; the first ordinary pre-eclampsia, a prolonged functional disturbance with little histological change and that mainly in the kidney; the second, an acute pathological disturbance usually developing in patients who have the first.

\section{Place for Caesarean Section}

Apart from the case that fails to go into labour after induction there is no place for caesarean section in eclasmpsia. Stroganoff taught that the membranes should be ruptured if the patient had three or four fits after the commencement of treatment, and it may be necessary to rupture the membranes after the fits have been controlled. It 윽 is probably true to say that today the continuance $D$ of fits after treatment would indicate that the treatment is inefficient.

*The generalized Shwartzman reaction is produced $N$ in non-pregnant animals by giving a ' preparing' dose of $N$ certain toxins intravenously, followed by a second $\omega$ 'provoking' dose intravenously. This second injection produces a reaction in many organs similar to 0 that found in eclampsia, cortical necrosis, etc. In $\frac{}{\mathbb{D}}$ pregnant animals the generalized Shwartzman reaction $\mathscr{D}$ has been observed to occur without the 'preparing'? injection. 
Some consider that caesarean section should be done on the fulminating case of pre-eclampsia which does not respond to treatment. Also in severe pre-eclampsia there would appear to be another place for caesarean section. In the Jessop Hospital out of 193 cases of toxaemia in which a surgical termination of pregnancy was done, $5 \mathrm{I}$ were less than 36 weeks pregnant. Of these $5 \mathrm{I}$, caesarean section was done $\mathrm{I} 4$ times and artificial rupture of the membranes 37 times. Three caesarean section infants and I I surgically induced infants were lost. In the 142 cases of induction over 36 weeks only five infants died.

Examination of the cause of death of infants under 36 weeks shows:-

\section{1 cases under 36 weeks}

Caesarean Section 14. Foetal deaths 3: Atelectasis 2, Broncho Pneumonia I.

Surgical Induction 37. Foetal deaths II; Intra-cranial haem 5; I.C.H. No P.M. I ; Intrauterine death after A.R.M. 4; Prolapsed Cord I.

The noticeable fact is that the deaths following caesarean section are all due to post-natal conditions, and the deaths following surgical induction are almost all due to intrapartum conditions, and, therefore, might have been avoided by caesarean section.

Examination of the case histories of the surgical induction group under 36 weeks did not show any significant difference in the length or severity of toxaemia between those with live babies and those with dead. But the dead babies were almost all under $4 \mathrm{lb}$. and the live babies were almost all over $4 \mathrm{lb}$. On the other hand, of babies under $4 \mathrm{lb}$. delivered by caesarean section most survived.

This suggests that caesarean section should be done on cases where severe toxaemia has developed comparatively early and is tending to become worse despite treatment-cases often about 32 to 34 weeks, and in all cases where the baby appears to be less than $4 \mathrm{lb}$. in weight. These babies are liable to intra-cranial haemorrhage.

There is support for this; Dieckmann and Brown have shown that the toxic baby of $1,000 \mathrm{~g}$. (2 lb. 2 oz.) to 2,000 g. $(4 \mathrm{lb} .4 \mathrm{oz}$.) has a better chance of survival if delivered abdominally.

New methods of treatment may reduce the incidence of prematurity, but if it becomes necessary to terminate the pregnancy while the foetus is less than $4 \mathrm{lb}$., the above argument would still stand.

\section{Treatment}

Because the etiology is not known the treatment of eclampsia has varied considerably even in recent years. Attempts to eliminate toxins gave place to sedation or a combination of both, and now hypotensive drugs are being used with the promise of improved results.

It need hardly be said that rest and salt restriction and adequate nutrition are likely to remain basic factors in prevention.

\section{Sedation}

Nursing. During treatment by sedation good nursing is essential and it is best to have the patient in a single room. It is not necessary for the room to be darkened but the patient should be protected from stimulation of the senses by sudden changes in the intensity of light, sound, or touch. If there is pulmonary oedema the comatose patient should not be left lying in one position for long, and should be protected from injury during fits. The airway must be kept free.

Treatment by sedation is associated with the name of Stroganoff. It aims at lowering the patient's perception of stimuli and neuronal excitability, thus stopping fits. If fits are allowed to continue the patient's condition usually deteriorates rapidly. Stroganoff induced heavy sedation with morphine, chloral hydrate, and chloroform in addition for any manipulation such as catheterization or vaginal examination. Later magnesium sulphate replaced chloral hydrate and chloroform was replaced by other less toxic anaesthetics. Sodium pentothal, paraldehyde and other sedatives are also used successfully but all have some disadvantages. McCall (1952) has shown that heavy sedation, especially by the intravenously administered barbiturates, depresses the oxygen metabolism of the brain. Sedation has to be deep and patients with eclampsia often have respiratory difficulty and diminished cough reflex. Broncho-pneumonia is a common complication. Collins (I955) recommends tracheotomy in cases where there is great respiratory difficulty. It facilitates the removal of bronchial secretions and the administration of oxygen. Vomiting is sometimes persistent with danger of inspiration of the vomitus; gastric suction is then necessary.

Chloroform is generally condemned because of its toxicity but in our experience when it is properly administered with ample air or oxygen, as an adjuvant to other forms of sedation, and only for short intervals to facilitate manipulations such as catheterization or vaginal examination, the maternal mortality is no higher than when other anaesthetics are used. In the Jessop Hospital in the ten years 1940 to 1949 , there were I 15 cases of eclampsia with six maternal deaths, and of these IOI cases were given chloroform with four maternal deaths; the other two patients who died did not receive chloroform. This maternal mortality rate compares favourably with other records for that time. Morphine is in every doctor's bag, and is 
most useful when eclampsia occurs in the patient's home, yet it has a depressive effect on renal function (Kraushaar et al. 1949), and depresses maternal and foetal respiration. Magnesium sulphate acts as a depressant of the central nervous system and blocks muscular contraction produced either by electrical stimulation or by drugs, but animals are rendered unconscious before the muscles lose their ability to respond to stimulation. Through its central action the blood pressure is lowered (Goodman and Gilman 1945).

The results of sedative treatment in I,O7I cases collected by Stern and Burnett, excluding Avertin, showed an overall maternal mortality of 7.56 per cent. and in 840 cases the foetal mortality was 29.17 per cent.

The methods of sedative treatment are numerous and it is not proposed to give details here. The use of Avertin or of hypotensive drugs alone or combined with basal sedation appear to be replacing the Stroganoff treatment.

\section{Bromethol, 'Avertin'}

Treatment with Bromethol (Avertin) was reintroduced by Dewar and Morris (1947) and the method has been adopted in many hospitals. The published results are better than by other sedative methods. Working in a region which included a large rural area they found that patients, after the initial dose, could be transported long distances to hospital: no patient developed fits in the ambulance. Bromethol appears to be a powerful anticonvulsant. The improved results may be due to its hypotensive effect in combination with its sedative effect. The blood pressure drops by an average of $55 \mathrm{~mm}$. $\mathrm{Hg}$. after its use.

The initial dose is about $0.0875 \mathrm{ml}$. per $\mathrm{Kg}$. of body weight of the concentrated bromethol fluid. This can be repeated if there are signs of restlessness but it is usually three hours after the first dose before a second dose is necessary. A third or later dose should not be given within a period of three hours following the preceding dose. More than six doses should not be given. In preparing each dose for rectal administration the manufacturers instructions must be followed closely. It is made up into a 3 per cent. solution in distilled water at $40^{\circ} \mathrm{C}$. and must then be tested with congo red to exclude breakdown products, which cause proctitis. If the rectal injection is given slowly the patient will usually retain it. The drug takes effect in about 20 minutes.

Stern and Burnett collected i 49 cases treated by this method and found the maternal mortality to be 4.03 per cent. and the foetal mortality, 32.58 per cent.

\section{Hypotensive Drugs}

Extracts of veratrum viride have been used in eclampsia for many years in conjunction with other treatment, but the side effects were dangerous, and it was regarded as a desperate remedy. Veratrone, a purified extract containing many alkaloids, was introduced in 1940. Stern and Burnett have collected from the literature reports of 498 cases with nine maternal deaths, a mortality of 1.81 per cent. This is a considerable improvement upon any other group collected from various sources. It should be noted that the hypotensive effect of the drug was relied upon without resort to sedative drugs, though Stern and Burnett in their own cases gave Mag. Sulph. as well.

In comparing mortality figures it is well to remember that eclampsia appears to be less severe in recent years. The mortality figures for sedative treatment are improving. In the Jessop Hospital the maternal mortality 1938 to 1946 , was 9.17 per cent. of 109 cases and 1947 to 1955 , it was 3.8 per cent. of 78 cases treated by magnesium sulphate Cases treated by hypotensive drugs are all recent cases.

\section{Protoveratrine}

Recently, Puroverine, an extract of veratrum album has become available. It contains only two closely related alkaloids, protoveratrine $A$ and $B$, the chemical difference between them being of a minor nature. They are present in a constan ratio of $2: 1$. These alkaloids are said to be found only in veratrum album. Since the first reports of the use of Puroverine in severe pre-eclampsia and eclampsia are encouraging, a brief summary of its clinical and pharmacological properties is useful.

I. A reduction in arterial blood pressure associated with peripheral vasodilatation is induced by reflex mechanisms the most important afferent receptors being in the region of the left coronary artery. The efferent pathway is not known.

2. It induces bradycardia which can be abolished by atropine without a significant reduction in the hypotensive effect. It reduces cardiac work.

3. There is a digitalis-like action on the decompensated heart.

4. The peripheral vascular resistance of the kidney is reduced. Provided the decrease in blood pressure is gradual, renal blood flow is not decreased. If the blood pressure falls too rapidly renal blood flow is transiently reduced.

5. A decrease in the cerebral vascular resistance.

6. A reduction in peripheral resistance in forearm and foot.

7. The uterine blood flow in pre-eclampsia is increased two or three times Morris (1955).

An advantage of treatment by hypotensive drugs is that the nursing is simplified because the 
patient remains fully conscious and co-operative and there is no tendency to pulmonary embarrassment. Krupp et al. (1956) stress the need to adapt the dosage to the requirements of each patient. They aim at reducing the blood pressure to about $140 / 90$ in severe cases and they notice that albuminuria and oedema steadily decline after the commencement of treatment. Basal medication given to all cases is 0.5 to $\mathrm{I} \mathrm{mg}$. of protoveratrine orally every two to four hours until the blood pressure falls to the desired level. The usual maintenance dose is $0.5 \mathrm{mg}$. every four hours. In cases of severe pre-eclampsia and eclampsia, in addition to the basal dose, they give 0.1 to $0.5 \mathrm{mg}$. protoperatrine intravenously in 1,000 c.c. of 5 per cent. dextrose in water at a rate of 30 drops per minute. The rate of infusion is increased if the blood pressure has not fallen to the desired level within 30 minutes. If within another 30 minutes the blood pressure is still not responding $0.1 \mathrm{mg}$ of proveratrine is given slowly over a period of two minutes directly into the infusion tube. This injection is repeated as often as is necessary to maintain the blood pressure at the desired level. It is necessary to record the blood pressure frequently.

Toxic manifestations can usually be controlled easily. Bradycardia responds to atropine and hypotension to ephedrine. If vomiting is troublesome it may be necessary to reduce the dose but it can usually be relieved by aluminium hydroxide mixture.

\section{Apresoline}

Apresoline has a potent hypotensive effect, increases the renal blood flow and the cerebral blood flow. Its effect on the uterine blood flow is not yet known. Its mode of action is probably central and is different from other hypotensive drugs. Side effects are common and increase as the blood pressure falls but subside when fairly normal levels are attained (McCall 1952).

\section{Hexamethoneum}

Morris (I955) thinks that the Hexamethonium compounds concentrate in the liquor amnii predisposing the infant to ileus or pneumonia. Therefore, their use should not be prolonged.

\section{Rauwolfia}

This group combines a sedative action with hypotension and is useful alone or in combinition with other hypotensive drugs, especially in chronic hypertensive states in pregnancy.

\section{Summary}

Reports indicate that the hypotensive drugs are of great value in the treatment of eclampsia. The pharmacological action of protoveratrine and Apresoline seems to be ideal for the treatment of the hypertensive states of pregnancy-depression of blood pressure, increase in the cerebral and renal blood flow, and in the case of protoveratrine increase in the uterine blood flow. The first reports are encouraging in regard to the mother, but not as yet in regard to the foetus. If the drugs can be tolerated for long without the development of resistance or unpleasant side-effect, there is hope that their administration early in the disease by preventing a decrease in placental blood flow may be beneficial to the foetus as well, even if they do not alter the fundamental cause of the ischaemia. If placental ischaemia is the initial cause then indeed we are at the beginning of a new era in the treatment of pre-eclampsia and eclampsia.

\section{BIBLIOGRAPHY}

BASTIAANSE, M. A. VAN BOUWDIJK, and MASTBOOM, J. L. (I950), 'Toxaemias of Pregnancy,' Ciba Foundation * Symposium, Churchill, London.

BECKER, J. C. (1948), f. Obstet Gynaec. Brit. Emp., 55, 756.

BROWNE, F. J. (r950), ' Postgraduate Obstetrics and Gynaecology,، Butterworth \& Co. Ltd., London.

BROWNE, J. C. MCL., and VEALL, N. (1953), f. Obstet. Gynaec. Brit. Emp., 60, 141 .

COLLINS, G. C. (1955), Postgrad. med. F., 17, 259.

DEWAR, J. B., and MORRIS, W. I. C. (1947), f. Obstet. Gynaec. Brit. Emp., 54, 417.

DIECKMANN, W. J., and BROWN, I. (1939), Amer. F. Obstet. Gynaec., 33, 214.

GOODMAN and GILLMAN (1941), 'The Pharmacological Basis of Therapeutics,' The Macmillan Company, New York.

GOVAN, A. T. D. (1954), F. Path. Bact., 67, 311 .

HUGHES, E. C., LLOYD, C. W., JONES, D., LOBOTSKY, J., RIENZO, J.'S., and AVERY, G. M. (1954), Amer. F. Obstet. Gynaec., 67, 782.

JAMES, J. R. E. (1955), F. Obstet. Gynaec. Brit. Emp., 62, 704. KELLAR, R. J. (1955), Ibid., 62, 683.

KELLAR, R. J., and SUTHERLAND, J. K. (I94I), Ibid., 48, 487. KRAUSHAAR, O. F., BRADBURY, J. T., WANG, Y. K., and BROWN, W. E. (I949), Amer. F. Obstet.'Gynaec., 57, 302.

KRUPP, P. J., PIERCE, C., FARRIS, C., and JACOBS, A. (1956), Ibid., $7 \mathrm{I}, 247$.

LLOYD, C. W., HUGHES, E. C., LOBOTSKY, J., RIENZO, J., and AVERY, G. M. (1952), 手. Clin. Invest., 3I, 1056.

MCCALL, M. L. (1949), Surg. Gynaec. Obstet., 89, 71 5.

MCCALL, M. L. (1953), Amer. F. Obstet. Gynaec., 66, ror 5.

MCCALL, M. L., and TAYLOR, H. W. (1952), f. Amer. med Ass., 149, 51 .

MCKAY, D. G., MERRILL, S. J., WEINER, A. E., HERTIG, A. T., and REID, D. E. (1953), Amer. 'f. Obstet. Gynaec., 66, 507.

MORRIS, N. (1955), f. Obstet. Gynaec. Brit. Emp., 62, 696.

MORRIS, N., OSBORNE, S. B., and WRIGHT, H. P. (1955), Lancet, $i, 323$.

ROWNTREE, L. G. (1923), Arch. Intern. Med., 32, 157.

SHEEHAN, H. L. (1950), ' Toxaemias of Pregnancy,' Ciba Foundation Symposium, Churchill, London.

SOPHIAN, J. (1953), 'Toxaemias of Pregnancy,' Butterworth \& Co. Ltd., London.

STERN, D. M., and BURNETT, C. W. F. (1954): F. Obstet. Gynaec. Brit. Emp., 6r, 590.

TATUM, H. J. (1954), Amer. F. Obstet. Gynaec., 67, 1197.

THEOBALD, G. W. (1955), 'The Pregnancy Toxaemias,' Henry Kimpton, London.

WETTLEY (1938), quoted by Bastiaanse and Mastboom (1950). YOUNG, J. (1914), Proc. Roy. Soc. Med., 7, 307.

YOUNG, J. (1942), F. Obstet. Gynaec. Brit. Emp., 49, 22 I. 